\title{
Analysis of Impact of Mathematics Courses though in Federal Polytechnics on Newly Admitted Students in North Eastern Nigeria
}

\author{
Mohammed Usman
}

\begin{abstract}
This research work compared Students' performance in Mathematicsin Senior School Certificate Examination (SSCE) to that of their Mathematicscourses though in first semester ND I from Federal Polytechnics in North Eastern state of Nigeria. Samples of Students' SSCE grade together with their corresponding ND I grade point (GP) were drawn from the files and record of the selected Student using simple random sampling. The information were collected from four (4) Federal Polytechnics, and the average of their GPs was taken and the SSCE grades were converted to GP equivalent to that of ND.Pearson correlation coefficient was employed to the data, and the result shows a very weak relationship of $\mathbf{r}=\mathbf{0 . 0 3 7 5}$ between their two grade points. This indicates that some students' resultsdoesnot correlate with their performance in ND Mathematics courses. The study also revealed that, there is significant differences in their performance based on z-test for two sample means. Outcome of the analysis may serve as yard stick to stakeholders to investigate further on how student write their SSCE or ND examinations in our various Institutions.Appropriate recommendation was made based on the result of the research work.
\end{abstract}

Index Terms - ND Mathematics, Pearson Correlation Coefficient, SSCE, Two Sample z-Tests

\section{INTRODUCTION}

Mathematics is the language of science and engineering describing our understanding of all that we observe. As a subject, it affects all aspects like social, economic, political, geographical, scientific and technological aspects in different degrees. Mathematics expresses itself everywhere in every facet of life - in nature all around us, and in the technologies in our hands. The interrelationshipbetween mathematics, development and advancement of humans shows how this subject is important in life for its numeral and symbolic behaviors, it is more related to the scientific and technological facets of man's world than to any other aspect as it occurs and reoccurs in the physical and natural sciences. It can be realized that the basic skills underlying entire technological skills are the control of the mathematical tools. According to [1], mathematical skill is extremely important not only for the higher education aspiring section, but also success in several competitive examinations for jobs depend upon the basic understanding in mathematics.

Students' poor performance in mathematics over the years has been attributed to the fact that the subject is difficult. In the same view, student's performance in mathematics tests

Mohammed Usman (PhD), Department of Statistics, Federal Polytechnic Bali, Taraba State, Nigeria. has been observed to vary from person to person and from school to school. [2] revealed that academic performances as well as mathematics performances of the government and private schools are better than the schools not getting government aids and also the study revealed that mathematics performances of schools are positively correlated with the academic performance of school indicated by school leaving pass percentage and with the performances in subjects other than mathematics.

Mathematics is a fundamental segment of human thought and logic, and integral to attempts at mutual comprehending the universe and ourselves. Mathematics provides a prolific way of building mental discipline and encourages scientific reasoning and mental hardship. Students' mathematicalperformance has become a matter of great concern to all stakeholders such as: parents, teachers,schools and government as whole. There has been clamor of dissatisfaction and disenchantment by mathematics lecturers and complain over the performance of the students, these students may have passed mathematics in SSCE at credit level but still failed most of the ND Mathematical courses. This apparent contradiction between performance in SSCE and ND semester results has prompted the researcher to find out whether there is correlation between the Students performance in SSCE and ND Mathematics. And also to further compare their mathematical result at entry point as part of the requirements for their admission in SSCE and that of ND I first semester results in Mathematics (MTH 111)Logic and Linear algebra, (MTH 112) Functions \& Geometry, (STA 111) Descriptive Statistics I and (STA 112) Elementary Probability Theory average grade with a view to determine the immediate and slight causes for this contradiction.

The importance of mathematics in national development is so high that the Federal Republic of Nigeria enshrined mathematics in the National Policy on Education as a core (compulsory) subject for all primary and secondary schools students in Nigeria [3]. Its inclusion as a pre-requisite for admission into science and technology based courses in the Nigerian tertiary institutions is basically because of the recognition of the indispensable role it plays in the advancement of science and technology of any nation [4]. Mathematics is to a nation what protein is to a young human organism. As a vital tool for the understanding and application of science and technology, the subject plays the necessary role of a precursor and harbinger to the much needed technological and natural development of the developing nations of the world [5]. Consequently, students are being encouraged to take up science and technology 
related disciplines. Globally today, scientific methods persuade literally field of human endeavour and play a fundamental role in economic development of any country. In our match toward scientific and technological advancement and following our aspiration to be among the first twenty economies in the world by the year 2020 [6], [7]

Mathematics is vital to our days to day natural activities. There is nothing an individual would do in a day that would not have the application of some mathematical concepts. Despite such applications that are important to our daily lives, it still shows that students dread the subject. Even the society talk of how difficult and abstract the subject is. Ever since, schools have tried to determine the performance of students through oral recitation, written test or actual performance on certain skills to the extent in which teaching and learning have resulted in success. Too often, the results of the measurements have failed to yield adequate appraisal of the learning that supposedly had taken place [8]. [9], Compared "the relationship between admission grades and performance of students in the first professional examination in a new medical School" and also another study conducted independently by [10]. [11] showed clearly that there was no correlation between students' Admission grades in Joint Admission and Matriculation Examination (JAME) with their performance in the University of Ibadan Medical School Both Studies showed that the SSCE scores are a better predictor of performance at pre-Clinical and 100 level examinations respectively than the JAME scores. Pre-ND study serves as a preparatory stage for student to get into ND1.

\section{METHODOLOGY}

Quantitative research design is regularly used to recognize the associations between variables, test conceptual models, determine the opinion/view of a given group of samples [12]. Thus, a measures of evaluations by means of quantitative research design was established in collecting relevant data necessary for the research work from Federal Polytechnics of
North East (NE) zone of Nigeria. The North East Geopolitical Zone of Nigeria covers close to one-third $\left(280,419 \mathrm{~km}^{2}\right)$ of Nigeria's land area $\left(909,890 \mathrm{~km}^{2}\right)$. It comprises six (6) states: Adamawa, Bauchi, Borno, Gombe, Taraba and Yobe. According to projections for 2011 by the National Bureau of Statistics (NBS), these States have 13.5\% (i.e. 23,558,674) of Nigeria's population which is put at $173,905,439$. Additionally, the Zone shares international borders with three countries: Republic of Cameroon to the East, Republic of Chad to the North East and Niger Republic to the North.

The research had considered four (4) Federal Polytechnic from thiszone which comprises Federal Polytechnic Bali, Federal Polytechnic Bauchi, Federal Polytechnic Mubi and Federal Polytechnic Damaturu. Two Departments were considered from School of Science and Technology (i.e. Computer Science and Statistics) in each of these Polytechnics. Records of ND I students were selected at random from these Departments and their Mathematical grade in Secondary School Certificate Examination (SSCE) werecollected and recorded together with their GPA in linear Algebra and Logic (MTH 111), Functions and Geometry (MTH 112), Descriptive Statistics I (STA 111) and Elementary Probability Theory (STA 112) for 2017/2018 academic session. The samples of size 15 and 30 were drawnfrom Statistics and Computer Departments respectively, using simple random sampling techniques, except for Statistics Department Federal Polytechnic Mubi where only 13 students were selected. The sampling was carried out based on proportion of the number of students admitted in the Department. The SSCE grades were converted to grade point (GP) equivalent to that of Diploma and average of the four GPAs of the four courses were taken and considered as their ND Mathematics grade point using grading system given in Table I. The two grade points werethen compared for the individual Institution and combine using Pearson correlation coefficient.

Table I: Unified Polytechnic and SSCE Grading systems

\begin{tabular}{|c|c|c|c|c|c|}
\hline SSCE Marks & WAEC Grade & NECO Grade & $\begin{array}{c}\text { Fed. Poly } \\
\text { Marks }\end{array}$ & Unified Grading & CGPA \\
\hline $80-100$ & $\mathrm{~A}_{1}$ & $\mathrm{~A}$ & $75-100$ & $\mathrm{~A}$ & 4.00 \\
\hline $70-79$ & $\mathrm{~B}_{2}$ & $\mathrm{~B}$ & $70-74$ & $\mathrm{AB}$ & 3.50 \\
\hline $65-69$ & $\mathrm{~B}_{3}$ & $\mathrm{C}$ & $65-69$ & $\mathrm{~B}$ & 3.25 \\
\hline $60-64$ & $\mathrm{C}_{4}$ & $\mathrm{D}$ & $60-64$ & $\mathrm{BC}$ & \\
\hline $55-59$ & $\mathrm{C}_{5}$ & & $55-59$ & $\mathrm{C}$ & 2.00 \\
\hline $50-54$ & $\mathrm{C}_{6}$ & & $50-54$ & $\mathrm{D}$ & 2.50 \\
\hline $45-49$ & $\mathrm{D}_{7}$ & $\mathrm{E}$ & $45-49$ & $\mathrm{E}$ & 2.25 \\
\hline $40-44$ & $\mathrm{E}_{8}$ & & $40-44$ & $\mathrm{~F}$ & 2.00 \\
\hline $0-39$ & $\mathrm{~F}_{9}$ & $\mathrm{~F}$ & $0-39$ & 0.00 \\
\hline
\end{tabular}

Source: [13]

Pearson correlation coefficient is a measure of the strength of the linear relationship between two variables. It is referred to as Pearson's correlation or simply as the correlation coefficient. If the relationship between the variables is not linear, then the correlation coefficient does not adequately represent the strength of the relationship between the variables [14]. There are five assumptions that are made with respect to Pearson's correlation:

$>$ The variables must be either interval or ratio measurements

$>$ The variables must be approximately normally distributed

$>$ There is a linear relationship between the two variables

$>$ Outliers are either kept to a minimum or are removed entirely.

$>$ There is homoscedasticity of the data.

The correlation coefficient is estimated using by. 


$$
r=\frac{n \sum x y-\sum x \sum y}{\sqrt{\left(n \sum x^{2}-\left(\sum x\right)^{2}\right)\left(n \sum y^{2}-\left(\sum y\right)^{2}\right)}} \quad 1
$$

To interpret the correlation coefficient $r$. we use $r^{2}$ which is called the coefficient of determination. The quantity $r^{2} \times 100 \%$ is the amount of variation in the values of the variable $y$ which is accounted for the linear relationship with the variable $x$.

Correlation is an effect size and so we can verbally describe the strength of the correlation using the guide that [15] suggests for the absolute value of $r$ : $0.00-0.19$ "Very weak", $0.20-0.39$ "weak", $0.40-0.59$ "moderate", 0.60 0.79 "strong", and $0.80-1.00$ "very strong". Note: 1) the correlation coefficient does not relate to the gradient beyond sharing its positive or negative sign. 2) The correlation coefficient is a measure of linear relationship and thus a value of $\mathrm{r}=0$ does not imply there is no relationship between the variables. If a scatterplot shows $r=0$ which implies no (linear) correlation however there is a perfect quadratic relationship [14].

This test statistics is used in situations such as the comparison of the income level of two regions, the nitrogen content of two lakes, performance of two group of students or the effectiveness of two drugs. There are several statistical tests available for the comparison of the center of two populations. This procedure is specific to the two-sample z-test assuming known and equal variance. If those assumptions are not likely to be met, another testing procedure could be used.

If we assume that $\mu_{1}$ and $\mu_{2}$ represent the means of the two populations of interest, where $\mu_{1}$ represent the mean performance of the students in SSCE and $\mu_{2}$ represent their mean performance in ND Mathematics, and that $\sigma=\mu_{1}-\mu_{2}$, the null hypothesis for comparing the two means is $H_{o}: \mu_{1}=$ $\mu_{2}$, (or $\left.H_{o}: \sigma=0\right)$. The alternative hypothesis can be two sided: $H_{o}: \mu_{1} \neq \mu_{2},\left(\right.$ or $\left.H_{o}: \sigma \neq 0\right)$, upper one-sided: $H_{o}: \mu_{1}>\mu_{2},\left(\right.$ or $\left.H_{o}: \sigma>0\right)$ or lower one-sided: $H_{o}: \mu_{1}<$ $\mu_{2}$, (or $\left.H_{o}: \sigma<0\right)$ depending upon the desire of the researcher or the protocol instructions. A suitable Type I error probability $(\alpha)$ is chosen for the test, the data is collected, and a $\mathrm{z}$-statistic is generated using the formula given below.

If $x_{1}$ and $x_{2}$ are two random variables representing SSCE and ND grade points following normal distribution with mean $\mu_{1}$ and $\mu_{2}$ and standard deviation $\sigma$, then the random variable $z$ is defined as follows.

$$
z=\frac{\bar{x}_{1}-\bar{x}_{2}}{\sigma \sqrt{\frac{1}{n_{1}}+\frac{1}{n_{2}}}}
$$

The null hypothesis is rejected in favor of the alternative hypotheses as follows;

$$
\begin{array}{ll}
\text { i) } & H_{1}: \mu_{1} \neq \mu_{2},\left(\text { or } H_{o}: \sigma \neq 0\right) \\
\text { ii) } & H_{1}: \mu_{1}>\mu_{2},\left(\text { or } H_{o}: \sigma>0\right) \\
\text { iii) } & H_{1}: \mu_{1}<\mu_{2},\left(\text { or } H_{o}: \sigma<0\right)
\end{array}
$$

if calculated value of $z$ is greater than table value for hypothesis (i) and (ii) (i.e. $z<z_{\alpha / 2}$ or $z>z_{1-\alpha / 2}$ and $z>$ $z_{\alpha}$ ) respectively and if calculated value $z$ is less than table value for hypothesis (iii) $\left(z<z_{\alpha}\right)$ [16]. Note that, comparing the $z$-statistic to the cut-off $z$-value (as shown here) is equivalent to comparing the $p$-value to $\alpha$.

\section{DATA ANALYSIS}

Data collected were organized in tabulation form and based on the assumption discussed above, we let $x$ represent the Grade point of the students in SSCE and $y$ represent their average Grade points in ND Mathematics. The formulae given above was adopted and the collected data was analyzed using Microsoft excel data analysis tools. Scatter plot were also plotted for each of the selected samples from these Polytechnics and presented in fig.1-4;

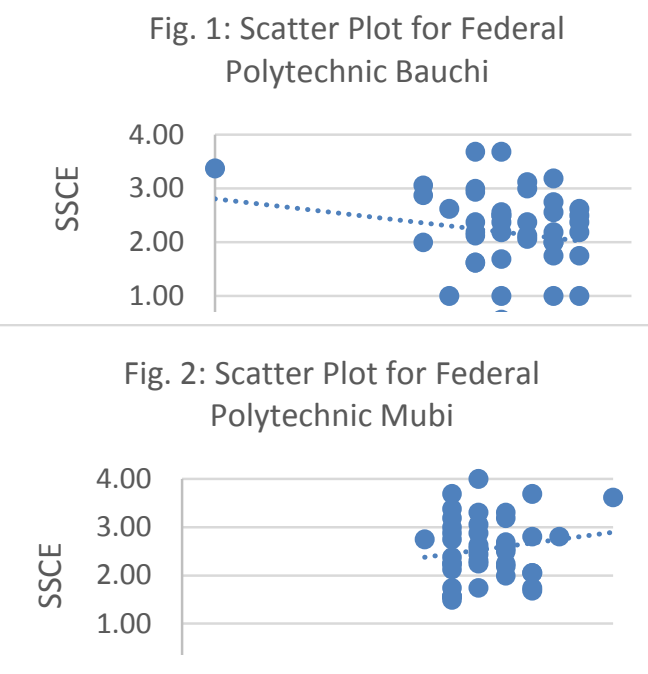

\section{Fig. 4: Scatter Plot for Federal} Polytechnic Bali

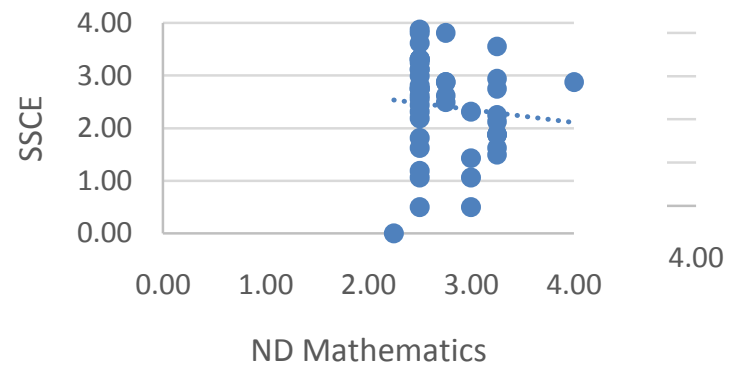

The Figure 1-4 shows scatter plots of the student grade points in SSCE and ND Mathematics for the four Polytechnic under study. The scatter plots for Federal Polytechnic Bauchi and Bali shows a decrease in the performance of the student compare to their SSCE result. While the plots for Federal Polytechnic Damaturu and Mubi shows an increase in their performance, more especially that of Damaturu.

Using Microsoft excel data analysis tools, Pearson correlation coefficient techniques was employed to the data and the result were presented in the table below. Student performance in SSCE from Federal Polytechnic Bauchi and Bali gives a very weak negative relationship with their performance in ND mathematics. While the SSCE performance of the student from Federal PolytechnicsMubi and Damaturu indicates very weakand weak relationship respectively with their ND Mathematics performance. 
Table II: Coefficients of Correlation for the Polytechnics under Study

\begin{tabular}{|l|l|l|l|l|}
\hline \multirow{2}{*}{ Correlation Coefficient } & Federal Polytechnics & Damaturu & Bali \\
\cline { 2 - 5 } & Bauchi & Mubi & 0.483 & -0.0979 \\
\hline$r$ & -0.1633 & 0.1599 & .
\end{tabular}

When the performance of the students from these Polytechnics were combine and analyze in the same vein. The coefficient of correlation shows a very weak positive relationship of $r=0.0375$

The data was further analyzed using z-test for two sample to compare if there is any significant difference between their performance in SSCE and ND Mathematical courses. The result of the analysis was displayed in the table below.

Table III: z-test for two sample means

\begin{tabular}{|l|l|l|}
\hline & SSCE & ND Mathematics \\
\hline Mean & 2.7781 & 2.4470 \\
\hline Sample Variance & 0.1751 & 0.7519 \\
\hline Standard error & 0.0314 & 0.0650 \\
\hline Observations & 178 & 178 \\
\hline Hypothesized Mean Difference & 0 & \\
\hline $\mathrm{Z}$ & 4.5884 & \\
\hline $\mathrm{P}(\mathrm{Z}<=\mathrm{z})$ two-tail & 0.0000045 & \\
\hline $\mathrm{Z}$ Critical two-tail & 1.96 & \\
\hline
\end{tabular}

The descriptive statistics shows that the average performance of the student in SSCE is slightly higher than their performance in ND Mathematics courses. Theresult revealed that, their entry requirement doesn't reflect their performance in ND Mathematics courses. The analysis based on z-test shows that $z_{c a l}=4.5884>z_{\alpha / 2}=1.96$, similarly $P(Z \leq Z=0.0000045<\alpha=0.05$, hence we reject the null hypothesis and conclude that, there is significant differences between the students' average performance in SSCE and ND Mathematics courses.The fair performance in ND Mathematics courses can be related to either lack of method of impacting knowledge on the part of the lecturers concerned in the Polytechnic or the credit scored by some of these student may be through magic. Note that, it is very courses in the Polytechnics lacks method of teaching. However, the stakeholders should look into how student manage to get their credit score to meet up with the entry requirement of getting admission into tertiary Institutions.

\section{DISCUSSION}

Having extensively analyzed the data using appropriate statistical tools, views and experience of fifty two (52) students from each of these Polytechnics under study weresought during the data collectionusing questionnaire. Among the questions asked were presented in the Table IV with their responses.

difficult to say that all the lecturers taking mathematics

Table IV: Responses of the Students interviewed using Questionnaire.

\begin{tabular}{|l|l|l|l|c|c|}
\hline & \multicolumn{3}{|c|}{$\begin{array}{c}\text { Did you offer any Mathematics course } \\
\text { in the Polytechnic? }\end{array}$} & \multirow{5}{*}{$\begin{array}{c}\text { Does the lesson taught in the Polytechnic } \\
\text { improve your understanding of Mathematics? }\end{array}$} \\
\cline { 2 - 3 } & Yes & No & Yes & No \\
\hline FPBau & 45 & 1 & 42 & 3 \\
\hline FPM & 39 & 0 & 40 & 2 \\
\hline FPD & 52 & 2 & 50 & 2 \\
\hline FPB & 49 & 49 & \\
\hline
\end{tabular}

More than $95 \%$ of the students responded positively and testified that, ND Mathematics courses have improved their understanding of Mathematics. The student were also asked, "why do you hate the subject?" with the following options "Not understanding the subject $(N U)$ Natural hate $(N H)$ Dislike teacher $(D T)$ Peer group $(P G)$ Method of teaching $(M T)$ " and their responses were Tabulate in Table $\mathrm{V}$.

Table V: Students' Responses on why they don't like Mathematics

\begin{tabular}{|l|l|l|l|l|l|}
\hline & NH & NU & $D T$ & $P G$ & $M T$ \\
\hline FPBau & 2 & 5 & 1 & 2 & 5 \\
\hline FPM & 2 & 9 & - & - & 3 \\
\hline FPD & - & 7 & 1 & - & 9 \\
\hline FPB & 4 & 6 & - & - & 8 \\
\hline Total & 8 & 27 & 2 & 2 & 25 \\
\hline
\end{tabular}

Most of the student dislike the subject either because of not understanding the subject or method of teaching. Method of teaching employed by some teachers in Secondary Schools that has nothing interesting or enjoyable to offer to the learnerscontributedseriously to poor performance of the students in Mathematics courses.Some teachers lack

knowledge of the subject matter and the methodologies for teaching mathematics. Nevertheless, some trained Mathematics teachers and lecturers also display lack of knowledge of mathematics concepts which raises doubts about the process by which they acquired the certificates they possess. These problems has led to some factors that causes 
poor performance in mathematics as spelled out by [17] and [18] that, the students' factors of poor academic performance were poor study habits, psychological adjustment problems, lack of interest in school programme, low retention, association with wrong peers, low achievement motivation and emotional problems.

\section{CONCLUSION AND RECOMMENDATION}

In conclusion, it is, therefore, important and imperative for Mathematics teachers to develop positive attitude towards the subject and make Mathematics interesting and appealing to students in order to help them develop a positive attitude towards it. Nevertheless, the problem of fair performance of students in ND Mathematics courses in Federal Polytechnics of North eastern state of Nigeria has been a concern for the stakeholders to make sure students were examine properly and prevent all sort of examination malpractice anywhere.

Thus, I will like to recommend that post JAMB examination to be re-introduce to allow each institution to assess their candidate in order to reduce what was happening in most of our Institution where students with distinction in SSCE end up failing ND mathematics courses.

Conferences, workshops and seminars on teacher self-efficacy should be organize to educate and enlighten teachers on the need for self-efficacy and its importance to effective learning.

Government should improve the condition of service of Nigerian workers more especially teachers to make them comfortable and satisfied with their job.According to Sule (2009), instructional strategies in mathematics will improve if some of the problems plaguing the study of mathematics in Nigeria are solved.

Parents should play a vital role by visiting their children at schools frequently to know their situationand academic performance.

\section{ACKNOWLEGMENT}

I am grateful to all my research assistances who work tirelessly in collecting data and relevant information for the success of the research work. This research was supported by a grant from the Nigerian Tertiary Education Trust Fund (TETFund).

\section{REFERENCES}

[1] Das, G. C. and Das, R. (2014) "A comparative study on students' mathematical performance between government and private secondary schools in Kamrup district, Assam" International Multidisciplinary e-Journal. ISSN 2277-4262. Pp 88-95

[2] Das, N. R., \&Barua, K. (2010): Secondary school education in Assam with special reference to Mathematics, IJMTL, 2010, October.

[3] Federal Republic of Nigeria (2004). National policy on education (Revised) Lagos, National Educational Research Council Press.

[4] Iyekekpolor, S. A. O. \&Bulus, O. S. (2009). Teachers' perception of the problems of secondary school mathematics teaching in Southern Taraba State. ABACUS: The Journal of the Mathematical Association of Nigeria, 34(10), 106-111.

[5] Zalmon, I. G. \&Wonu, N. (2017) "Comparative Analysis of Student Mathematics Achievement in West African Senior Secondary Certificate Examination in Nigeria". European Journal of Research and Reflection in Educational Sciences, Volume 5, No 1, ISSN 2056-5852

[6] Obioma, G., (2009). The predictive validity of public examination: A case study of Nigeria. A paper presented at the 33rd Annual
Conference of International Association of Educational Assessment (IAEA) held in Baku, 16-21.

[7] National Educational Research Council (2007). A study of the problems and issues of mathematics teaching in Nigeria: A report of NERC national task force on mathematics. Lagos, National Educational Research Council Press.

[8] Samuel H. Tsok, Shammah S. Kpanja\& Mary S. Hwere. (2013) “A Comparative Study of Student's Performance in S.S.C.E Mathematics and Pre-National Diploma (PRE-ND) Programmes Mathematics: A Case Study of Nasarawa State Polytechnic Lafia" Journal of Education and Practice, Volume 4, No 12. ISSN 2222-1735

[9] Salehdeen, H. M. \&Murtala, B. A. (2005) Relationship between Admissions grades and performances of students in the first professional examination in a new medical school: African Journal of Biomedical Research, Volume 8, No. 1, Pp, 57-57

[10] Oyebola, D. D. (2006). "The Importance of O'level grades in Medical School Admission: The University of Ado Ekiti Experience," Africa Journal of Biomedical Research, Volume 9, No. 1. Longman Nigeria Plc.

[11] Bamgboye E. A, Ogunnowo, B. E. \&Adewoye, E. O., (2001) Students Admission grades and their Performance at the Ibadan University Preclinical MBBS Examination. African Journal Med. \& Med. Sci. Volume 30, Pp, 207-211

[12] Christenson, J. D., \& Gutierrez, D. M. (2016). Using Qualitative, Quantitative, and Mixed Methods Research to Promote Family Therapy with Adolescents in Residential Settings. Contemporary Family Therapy, 38(1), 52-61. https://doi.org/10.1007/s10591-016-9374-x

[13] Unified Grade System (2018), Approved by the National Board for Technical Education and https://www.google.com/search?q=wassce+grading+system\&tbm

[14] David M. L. (2013). Values of the Person Correlation, HyperStat Online: An Introductory Statistics. http://davidmlane.com/hyperstat/

[15] Evans, J.D. (1996). Straightforward Statistics for the Behavioral Sciences. Brooks/Cole Publishing; Pacific Grove, Calif.: 1996.

[16] NCSS (2019). Two Sample z-Tests Assuming Equal Variance, Chapter 426.

https://ncss-wpengine.netdna-ssl.com>ncss $>$ pdf $>$ Procedures>PASSRetr ieved Sept, 2019

[17] Aremu, A. O. andSokan, B. O.(2003); A Multi-causal Evaluation of Academic Performance of Nigerian Learners: Issues and Implications for National Development. Department of Guidance of Counselling, University of Ibadan.

[18] Bakare, C.G.M.(1994); Mass Failure in Public Examinations: Some Psychological Perspectives. Monograph. Department of Guidance of Counselling, University of Ibadan.

[19] Sule, A. O. (2009). Improving instruction and achievement in mathematics at all levels of education in Nigeria. Journal of the Mathematical Association of Nigeria 34(1) 54-62

Mohammed Usman: Attended his earlier education at Gwange IV Primary School Maiduguri and proceeded to Government Teachers College Gwoza. His University education was in University of Maiduguri where he obtained Diploma in Mathematics Education and Bachelor of Science in Statistics. He obtained Masters \& Doctorate Degree in Statistics at University of Ilorin. The Author is currently Staff of Department of Statistics, Federal Polytechnic Bali, Taraba State, he is the Deputy Rector and Director Academic Planning of the Polytechnic. A pioneer Head of Department of Statistics and Dean School of Science and Technology and a visiting lecturing at Gombe State University. Member of the Nigerian Statistical Association (NSA), Professional Statisticians Society of Nigeria (PSSN), Teachers Registration Council of Nigeria (TRCN) and International Research and Development Institute (IRDI) Network. The author has published many articles in both National and International Journals and presently working on a book titled "Applied General Statistics for Intermediate level". 